\title{
Evaluating the aerobic xylene-degrading potential of the intrinsic microbial community of a legacy BTEX-contaminated aquifer by enrichment culturing coupled with multi-omics analysis: uncovering the role of Hydrogenophaga strains in xylene degradation
}

\author{
Sinchan Banerjee ${ }^{1} \cdot$ Anna Bedics $^{1} \cdot$ Péter Harkai $^{2} \cdot$ Balázs Kriszt $^{2} \cdot$ Nagaraju Alpula $^{1,3} \cdot$ András Táncsics $^{1}$ (D)
}

Received: 23 June 2021 / Accepted: 20 December 2021 / Published online: 6 January 2022

(c) The Author(s) 2022

\begin{abstract}
To develop effective bioremediation strategies, it is always important to explore autochthonous microbial community diversity using substrate-specific enrichment. The primary objective of this present study was to reveal the diversity of aerobic xylene-degrading bacteria at a legacy BTEX-contaminated site where xylene is the predominant contaminant, as well as to identify potential indigenous strains that could effectively degrade xylenes, in order to better understand the underlying facts about xylene degradation using a multi-omics approach. Henceforward, parallel aerobic microcosms were set up using different xylene isomers as the sole carbon source to investigate evolved bacterial communities using both culture-dependent and independent methods. Research outcome showed that the autochthonous community of this legacy BTEX-contaminated site has the capability to remove all of the xylene isomers from the environment aerobically employing different bacterial groups for different xylene isomers. Interestingly, polyphasic analysis of the enrichments disclose that the community composition of the $o$-xylene-degrading enrichment community was utterly distinct from that of the $m$-and $p$-xylene-degrading enrichments. Although in each of the enrichments Pseudomonas and Acidovorax were the dominant genera, in the case of $o$-xylene-degrading enrichment Rhodococcus was the main player. Among the isolates, two Hydogenophaga strains, belonging to the same genomic species, were obtained from $p$-xylene-degrading enrichment, substantially able to degrade aromatic hydrocarbons including xylene isomers aerobically. Comparative whole-genome analysis of the strains revealed different genomic adaptations to aromatic hydrocarbon degradation, providing an explanation on their different xylene isomer-degrading abilities.
\end{abstract}

Keywords Xylene $\cdot$ Hydrogenohaga $\cdot$ Groundwater $\cdot$ Aromatic hydrocarbons $\cdot$ Biodegradation $\cdot$ Catechol 2,3-dioxygenase

\section{Introduction}

Xylene is one of the volatile organic compounds composed of a central benzene ring with two methyl groups attached as substituents, arranged in three various positions to create three distinct isomers: $m$-xylene, $o$-xylene, and $p$-xylene (Marshall and Rodgers 2008; Kandyala et al. 2010; Yan and Zhou 2011). It is a toxic monoaromatic hydrocarbon and is highly mobile in the environment, either in the gaseous, liquid, or solid phase (Mazzeo et al. 2013). Among BTEX compounds, xylene is most commonly used as a solvent in industrial coatings and the petrochemical industry (Boonsaner et al. 2011). Only in the USA, the amount of xylenes (mixed isomers) released in 2012 from all factories was $7,482,435 \mathrm{~kg}$ (including disposal and release on-site and 
off-site) (US EPA-United States Environmental Protection Agency 2012). It could also be released into nature because of crude oil spillages during shipping, loading, and storage. As a result of these different practices and procedures, the deposition of xylene in soil and groundwater can pose a tremendous challenge to soil and groundwater resources (Kao and Wang 2000; Kandyala et al. 2010; Atlas and Hazen 2011; Das and Chandran 2011; Alrumman et al. 2015). Because of their relatively high water solubility, this type of contamination was often treated as a considerable threat to the primary drinking water reserves. Since xylene has been reported as toxic to the liver, kidneys, and central nervous system, once it enters into the body by skin contact or inhalation, hence, monitoring and removal of xylene from the environment have been regarded globally as a high priority (Kao and Wang 2000; Andreoni and Gianfreda 2007; Kandyala et al. 2010; Atlas and Hazen 2011; Das and Chandran 2011).

Although eradication of xylene and other petroleum hydrocarbons can be performed using physical, chemical, and biological approaches, microbial biodegradation is considered less expensive and one of the most promising alternatives means for cleaning up the environment from petroleum hydrocarbon contamination (Kovalick 1992; Vidali 2001; Jahn et al. 2005; Vieira et al. 2007; Silva et al. 2009; Lin et al. 2010; Das and Chandran 2011; Alrumman et al. 2015).

The technique of biodegradation uses microorganisms to treat contaminants by degrading organic compounds into less harmful material, such as $\mathrm{CO}_{2}$, methane, water, and inorganic salts, under both ex-situ or in-situ, aerobic or anaerobic conditions. BTEX biodegradation using microorganisms has also been established as an effective and environmentally friendly method (Delhoménie et al. 2003; Noguchi et al. 2014; Kim et al. 2014). There are several studies conducted that found the role of various microorganisms for effective degradation of xylene, including Alcaligenes xylosoxidans, Pseudomonas putida (Reardon et al. 2000; Yeom and Daugulis 2001; Robledo-Ortíz et al. 2011), Pandoraea sp. (Wang et al. 2015), and Rhodococcus sp., (Di Canito et al. 2018). A few isolates were reported to grow with $m$-xylene (Dolfing et al. 1990; Fries et al. 1994; Rabus and Widdel 1995; Harms et al. 1999; Morasch et al. 2004) or $o$-xylene (Harms et al. 1999; Morasch et al. 2004), whereas until now, only handful of studies have reported on pure cultures, which can degrade $p$-xylene anaerobically (Higashioka et al. 2012). So far, limited number of studies have been undertaken regarding xylene degradation by the autochthonous microbial community from decade-old xylene-contaminated site to develop effective strategies for bioremediation using biostimulation. To add further, not much have been investigated concerning the xylene biodegradation potential of the genus Hydrogenophaga, in spite of their noticeable presence in xylene-contaminated environments (Táncsics et al. 2010, 2012, 2013; Benedek et al. 2016). In the aerobic degradation of aromatic hydrocarbons ring-cleavage dioxygenases are playing a key role, by catalyzing aromatic ring-opening reactions. It is well known that in contaminated subsurface environments subfamily I.2.C-type catechol 2,3-dioxygenase $(C 23 O)$ genes are usually present in large diversity (Táncsics et al. 2013). Most of them are harbored by members of the Betaproteobacteriales (Táncsics et al. 2013) and some of them are involved in the microaerobic degradation of aromatics, e.g., toluene (Táncsics et al. 2020). Still, the role of both of these bacteria and the I.2.C-type $C 23 O$ genes in xylene degradation is unknown. Despite several studies, still, there are underlying information that need thorough investigation to uncover.

These aforementioned facts prompted us to explore structural changes in the autochthonous microbial communities in xylene isomer induced enrichments and uncover information about key indigenous degraders of a decade-old petroleumcontaminated aquifer. Nevertheless, this present study is the first one of its kind, where we furnished information about critical community shift induced by xylene isomers as sole carbon source and the detailed study of xylene degradation by Hydrogenophaga strains. Furthermore, comparative analysis of the whole-genome sequence of two Hydrogenophaga strains that belong to the same species with entirely different substrate utilization patterns shed light on the communityacquired functional capabilities.

\section{Materials and methods}

\section{Site description and sample collection}

Groundwater sample was obtained from a gasoline-contaminated site of Siklos, a town located in the south-west region of Hungary $\left(45^{\prime} 51^{\prime \prime} 25.8^{\circ} \mathrm{N}, 18^{\prime} 17^{\prime \prime} 32.3^{\circ} \mathrm{E}\right.$ ) (Táncsics et al. 2013) during February 2019. This site was contaminated by petroleum hydrocarbons due to accidental leakage of the underground storage tank of a former petrol station during the end of 1980 s, resulting in hydrocarbon contamination of surrounding soil and groundwater reserve. Groundwater sample was collected from the monitoring well No. ST2 located at the center of the contaminated zone from a depth of $\sim 2.5-4 \mathrm{~m}$. The sampled groundwater is mainly contaminated with xylene, benzene, ethylbenzene, and toluene. The site has been thoroughly studied and described by Táncsics et al. $(2012,2013)$ earlier. Physicochemical properties and BTEX concentration of contaminated groundwater are monitored orderly by an accredited laboratory (Wessling Hungary Ltd.) according to Hungarian Standard (MSZ) analytical techniques to enable the authorities to plan for strategic measures. The dissolved oxygen concentration and 
redox potential values were measured on-site using a WTW hand-held Meter Multi 350i (WTW, Germany). The sample was collected into sterile 1-L serum bottles, keeping no headspace, and transported to the laboratory, preserved at $4{ }^{\circ} \mathrm{C}$ in the dark for further investigation. Physicochemical characteristics of the sample are summarized in Table S1.

\section{Enrichment setup and evaluation of xylene degradation}

Enrichment microcosms were set up in duplicates (2 parallel) with contaminated groundwater sample from the Siklos site using $m$-, $p$-, and $o$-xylene as a sole carbon source under aerobic conditions $\left(\sim 7-8 \mathrm{mg} \mathrm{L}^{-1}\right.$ dissolved $\left.\mathrm{O}_{2}\right)$. For the enrichments, $45 \mathrm{~mL}$ minimal mineral salt (MS) medium (Fahy et al. 2006) supplemented with vitamins ( $1 \mathrm{mg} / \mathrm{L}$ thiamine, $15 \mu \mathrm{g} / \mathrm{L}$ biotin, and $20 \mu \mathrm{g} / \mathrm{L}$ vitamin $\mathrm{B}_{12}$ ) was used in $100-\mathrm{mL}$ serum bottles sealed with butyl-rubber septa and aluminium crimp seals. Subsequently, $m-, p-$, or $o$-xylene as sole carbon and energy sources were added to the enrichments at a final concentration of $1 \mathrm{mM}$ followed by inoculation with $5 \mathrm{~mL}$ of the contaminated groundwater sample. To ensure the strict aerobic conditions, the bottles were monitored non-invasively by Fibox 3 trace v3 fiber optic oxygen meter with PSt3 sensor spots (PreSens). The oxygen concentration was restored whenever needed by injecting sterile air $(0.2-\mu \mathrm{m}$ pore size filtered) through the butyl-rubber septa. The microcosms were incubated for 7 days in a shaking thermostat at $28{ }^{\circ} \mathrm{C}, 150 \mathrm{rpm}$. Then 5 -mL inoculum from each microcosm was transferred into a fresh medium. Similar transfers were made for consecutive 5 weeks. To monitor the consumption of xylene as the sole carbon source, the concentration of $m-, p-$, and $o$-xylene was measured for 5 thweek enrichment microcosms at 24-h interval by headspace analysis on an ISQ Single Quadrupole gas chromatographymass spectrometer (GC-MS) (Thermo Fischer Scientific) via a SLB-5 ms fused silica capillary column (Supelco Analytical). Uninoculated duplicate microcosms with $45 \mathrm{~mL}$ of medium and $1 \mathrm{mM}$ concentration of $m-, p$-, and $o$-xylene served as a negative control for GC-MS analysis. For the analysis, the oven temperature was set to $40^{\circ} \mathrm{C}$ for $3 \mathrm{~min}$, then ramped at a rate of $20{ }^{\circ} \mathrm{C} \mathrm{min}^{-1}$ to $190{ }^{\circ} \mathrm{C}$, and held for $1 \mathrm{~min}$. The mass spectrometer ran at $250^{\circ} \mathrm{C}$ in full scan mode.

\section{Community DNA isolation and T-RFLP fingerprinting}

Genomic DNA from the enrichments was isolated after five consecutive transfers. In order to do so, microbial biomasses were harvested from $45 \mathrm{~mL}$ of the enrichment by centrifuging at $2360 \mathrm{~g}$ at $4{ }^{\circ} \mathrm{C}$ for $10 \mathrm{~min}$ using a Rotanta 460 $\mathrm{R}$ (Hettich). According to the manufacturer's instructions, total community DNA was extracted from the pellet using the DNeasy Ultraclean Microbial Kit (Qiagen). Followed by isolation, the quality of DNA was analyzed in ethidium bromide stained $1 \%(\mathrm{w} / \mathrm{v})$ agarose gel electrophoresis. Moreover, the concentration of extracted DNA was measured using a NanoDrop One Microvolume UV-Vis spectrophotometer (Thermo Fisher Scientific, Waltham, MA, USA). To get a comprehensive view concerning the differences in the community structure in various enrichments and to decide on the enrichment sample that represents the phylogenetic diversity best among duplicates, for further 16S rRNA gene Illumina sequencing, terminal restriction fragment length polymorphism (T-RFLP) analysis was performed (Székely et al. 2009). For $16 \mathrm{~S}$ rDNA-based community profile study, the VIC-labeled amplicons were generated using 27f-VIC (5'-AGAGTTTGATCMTGGCTCAG- $3^{\prime}$ ) and $1492 \mathrm{r}$ primers (5'T ACGGYTACCTT GTTACGA C T T-3'). Amplification conditions were the same as described earlier by Benedek et al. (2016). All amplifications were achieved in a ProFlex PCR System (Life Technologies). The quality of amplified products was checked by electrophoresis on $1 \%$ agarose gels stained with ethidium bromide. The VIC-labeled $16 \mathrm{~S}$ rDNA were digested with $1 \mathrm{U} R s a \mathrm{I}$ (GT $\downarrow \mathrm{AC}$ ) (Thermo Fisher Scientific) for $1.5 \mathrm{~h}$ at $37^{\circ} \mathrm{C}$. The generated fluorescently labeled terminal restriction fragments (T-RFs) were purified by the ethanol precipitation method. After ethanol precipitation, fragments were separated on a Model 3130 Genetic Analyzer (Applied Biosystems), while using GeneMapper 4.0 software (Applied Biosystems), preliminary evaluation of electropherograms was performed. T-RFLP data were handled as described earlier (Farkas et al. 2017). Statistical analysis, such as cluster analysis (Bray-Curtis method) of the T-RFLP electropherograms, was performed using the PAST 3.26 software package (Hammer et al. 2001).

\section{Illumina 16S rRNA gene amplicon sequencing for community analysis}

Using the method of T-RFLP, one of the representatives among the duplicate enrichments were selected (M1, P1, O1) for amplicon sequencing for in-depth evaluation of community composition. The V3 and V4 variable regions of the 16S rRNA gene were amplified with the PCR primers suggested by Klindworth et al. (2013) to get pairedend $16 \mathrm{~S}$ rDNA amplicons. PCR was done according to the $16 \mathrm{~S}$ metagenomic sequencing library preparation guide of Illumina using KAPA HiFi HotStart Ready Mixet (KAPA Biosystems). Paired-end fragment reads were generated on an Illumina MiSeq sequencer using MiSeq Reagent Kit v3 (600-cycle) by SeqOmics Biotechnology Ltd. (Mórahalom, Hungary). Read numbers were as follows: 235,746 for enrichment M1, 246,389 for enrichment P1, and 245,628 for enrichment O1. Primary data analysis (base-calling) was conducted with Bbcl2fastq ${ }^{\wedge}$ software 
(v2.17.1.14, Illumina). Reads were quality and length trimmed in CLC Genomics Workbench Tool 9.5.1 using an error probability of $0.05(\mathrm{Q} 13)$ and a minimum length of 50 nucleotides as a threshold. Then the rimmed sequences were processed using mothur v1.41.1 (Schloss et al. 2009) as recommended by the MiSeq SOP page (http://www. mothur.org/wiki/MiSeq_SOP) (Kozich et al. 2013). Based on the alignment using the SILVA 132 SSURef NR99 database (Quast et al. 2013), sequences were assorted. Detection of chimeras was done with Mothur's uchime command (Edgar et al. 2011), and the "split.abund" command was also used to remove singleton reads according to Kunin et al. (2010). Ninety-seven-percent similarity threshold level was used to assign Operational Taxonomic Units (OTUs) as suggested by Tindall et al. (2010) for prokaryotic species delineation. Venn diagrams were generated by the mothur's venn command. Rarefaction curves (Fig. S1) showed high sequencing coverage in all samples. Sequence reads were deposited in NCBI under BioProject ID PRJNA704261.

\section{Identification of bacterial strains and sequencing of C230 gene}

Cultivable bacterial strains from the xylene-induced enrichments were isolates by serially diluting the homogeneous sample with physiological salt solution $(0.9 \% \mathrm{NaCl})$. Then $0.1 \mathrm{~mL}$ of serially diluted samples was spread on to R2A agar plates (protease peptone $0.5 \mathrm{~g}$, casamino acids $0.5 \mathrm{~g}$, yeast extract $0.5 \mathrm{~g}$, dextrose $0.5 \mathrm{~g}$, soluble starch $0.5 \mathrm{~g}$, dipotassium phosphate $0.3 \mathrm{~g}, \mathrm{MgSO}_{4} 7 \mathrm{H}_{2} \mathrm{O} 0.05 \mathrm{~g}$, sodium pyruvate $0.3 \mathrm{~g}$, agar $15 \mathrm{~g}, \mathrm{pH} 7 \pm 0.2$ ) (Sigma-Aldrich, Germany). After 1 week of incubation at $28{ }^{\circ} \mathrm{C}$, then colonies with different morphologies were purified using streak plate technique and maintained on R2A agar slants at $28{ }^{\circ} \mathrm{C}$. Genomic DNA of isolates was extracted from pure cultures grown on R2A agar slants using the UltraClean Microbial DNA Kit (Qiagen) following the manufacturer's instruction. Afterward, the $16 \mathrm{~S}$ rRNA and subfamily I.2.C-type $C 23 O$ genes of the isolates were amplified and sequenced. Detection and sequencing of subfamily I.2.C-type $C 23 O$ genes were performed by using the primers XYLE3f (5'-TGY TGG GAY GAR TGG GAY AA-3') and XYLE3r (5'-TCA SGT RTA SAC ITC SGT RAA-3') (Táncsics et al. 2012, 2013). The species-level identification of cultivable bacteria was assessed on the basis of 16S rRNA gene-based Sanger dideoxy chain termination sequencing using the universal bacterial primers 27F (5'-AGAGTTTGATC(A/C) TGGCTC AG-3') and 1492R (5'-TACGG(C/T) TACCTTGTTACGAC TT-3'). Sequencing of the $16 \mathrm{~S}$ rDNA and $C 23 O$ amplicons was performed according to Benedek et al. (2018).

The $16 \mathrm{~S}$ rRNA and $C 23 O$ gene sequences of the isolates were deposited to GenBank under the accession numbers MW647763-MW647782, MZ127192, and MW691988-MW691994 subsequently.

\section{BTEX-degradation analysis of the selected isolates}

Aerobic degradation ability of selected strains was accessed by GC-MS. In this study, importance was given to those isolated strains that belong to genera with the least available knowledge regarding their BTEX degradation potential, with particular emphasis on xylene degradation for further investigation. The experiment was conducted in triplicates of $100-\mathrm{mL}$ crimped serum bottles containing $50 \mathrm{~mL} \mathrm{MS}$ medium supplemented with different BTEX compounds as a carbon source at $5 \mathrm{mg} / \mathrm{L}$ concentration and kept aside for $24 \mathrm{~h}$ to provide time for the abiotic solution to reach the equilibrium state. Thereafter, investigational $100-\mu \mathrm{L}$ bacterial inoculum (OD600 0.5) was added to the serum bottles and uninoculated serum bottles served as negative controls. All of the bottles were kept for incubation at $28^{\circ} \mathrm{C}$ and 150 r.p.m. in a rotary shaker incubator. Biodegradation of BTEX compounds was measured at a regular interval of $24 \mathrm{~h}$ by headspace analysis in GC-MS as described earlier.

\section{Comparative whole-genome analysis of selected isolates}

Despite the fact that genus Hydrogenophaga contains excellent BTEX degraders (Fahy et al. 2008; Jechalke et al. 2013), unfortunately, it has not been studied with particular emphasis to our knowledge. Even though previous studies using the same contaminated groundwater sample showed the presence of this genera in different enrichments but never investigated thoroughly. Moreover, there is no such valuable xylene degradation data available to date concerning the isolated Hydrogenophaga spp. and their closest relatives. Therefore, to fill that knowledge gap, it was decided to investigate furthermore about the isolated Hydrogenophaga strains concerning their aromatic hydrocarbon degradation. The whole-genome sequencing of selected Hydrogenophaga strains was performed as described by Borsodi et al. (2019) by the SeqOmics Biotechnology Ltd. (Mórahalom, Hungary). De novo assembly and scaffolding was performed with SPAdes version 3.13.0 (Nurk et al. 2013). Automatic annotation of the genome was performed by the NCBI Prokaryotic Genomes Automatic Annotation Pipeline (PGAP) v4.5 (Tatusova et al. 2016) To determine digital DNA-DNA hybridization ( $\mathrm{DDDH})$ value between analyzed strains the Genome-to-Genome Distance Calculator (GGDC, https://ggdc.dsmz.de/, version 2.1) was used (Meier-Kolthoff et al. 2013). For the calculation of orthologous average nucleotide identity (OrthoANI) value between strains, the OAT software was used (Lee et al. 2016). To analyze metabolic potentials of the investigated Hydrogenophaga strains 
the genomes were annotated by using the Genoscope platform MAGE (Vallenet et al. 2009) as well. Subsequently, analysis was performed by combining automated annotation from MAGE and manual curation using information from MetaCyc (Caspi et al. 2014), KEGG (Kanehisa and Goto 2000), and UniProt (Bateman 2019). For the alignment of analyzed genomes the CLC Genomics Workbench version 21.0.3 (Qiagen) was used. For the identification of genomic islands the IslandViewer 4 was used (Bertelli et al. 2017).

The genome sequences of strain Hydrogenophaga sp. $\mathrm{D} 2 \mathrm{P} 1^{\mathrm{T}}$ and Hydrogenophaga sp. D2P3 have been deposited at the GenBank database under the WGS accession numbers VYGV00000000 and JAGPWB000000000.

\section{Results and discussion}

\section{Physicochemical analysis of investigated groundwater}

As the groundwater at the contaminated site is present under a thick layer of clay, the contaminated groundwater well upholds an oxygen-limited setting. Dissolved oxygen concentration values $(1.2 \mathrm{mg} / \mathrm{L})$ indicated the same hypothesis. The physicochemical data shown in Table S1 support the statement adequately. Moreover, the data suggest that the reducing condition is prevalent in the contaminated zone. Though the concentration of contaminants significantly decreased compared to the beginning of the contamination with time because of the autochthonous microbial community, the concentrations of some of the contaminants are still beyond the permissible limit according to Hungarian standards. Nowadays, the contaminated aquifer is overdominated with the contamination of xylene. Furthermore, the data shows the decreased concentration of nitrate and sulfate and increasing trend of $\mathrm{Fe}$ (II) and methane, which is presumably indicative of the presence of $\mathrm{Fe}$ (II) reducing and methanogenic organisms in deeper layers of the contaminated aquifer (Table S1).

\section{Xylene degradation by enriched communities}

Using the contaminated groundwater inoculum, aerobic (7-8 $\mathrm{mg} / \mathrm{L}$ dissolved oxygen) microcosms were set up in duplicates with $m-, p$-, and $o$-xylene as a sole source of carbon and energy. Enrichments were then transferred weekly for consecutive 5 weeks. The xylene degradation process by enrichments reflected that highly competent aerobic-degrading communities evolved in the enrichments by the fifth week. The carbon source in the enrichments was almost depleted by $24 \mathrm{~h}$ of incubation; $o$-xylene-degrading enrichments were the only exception
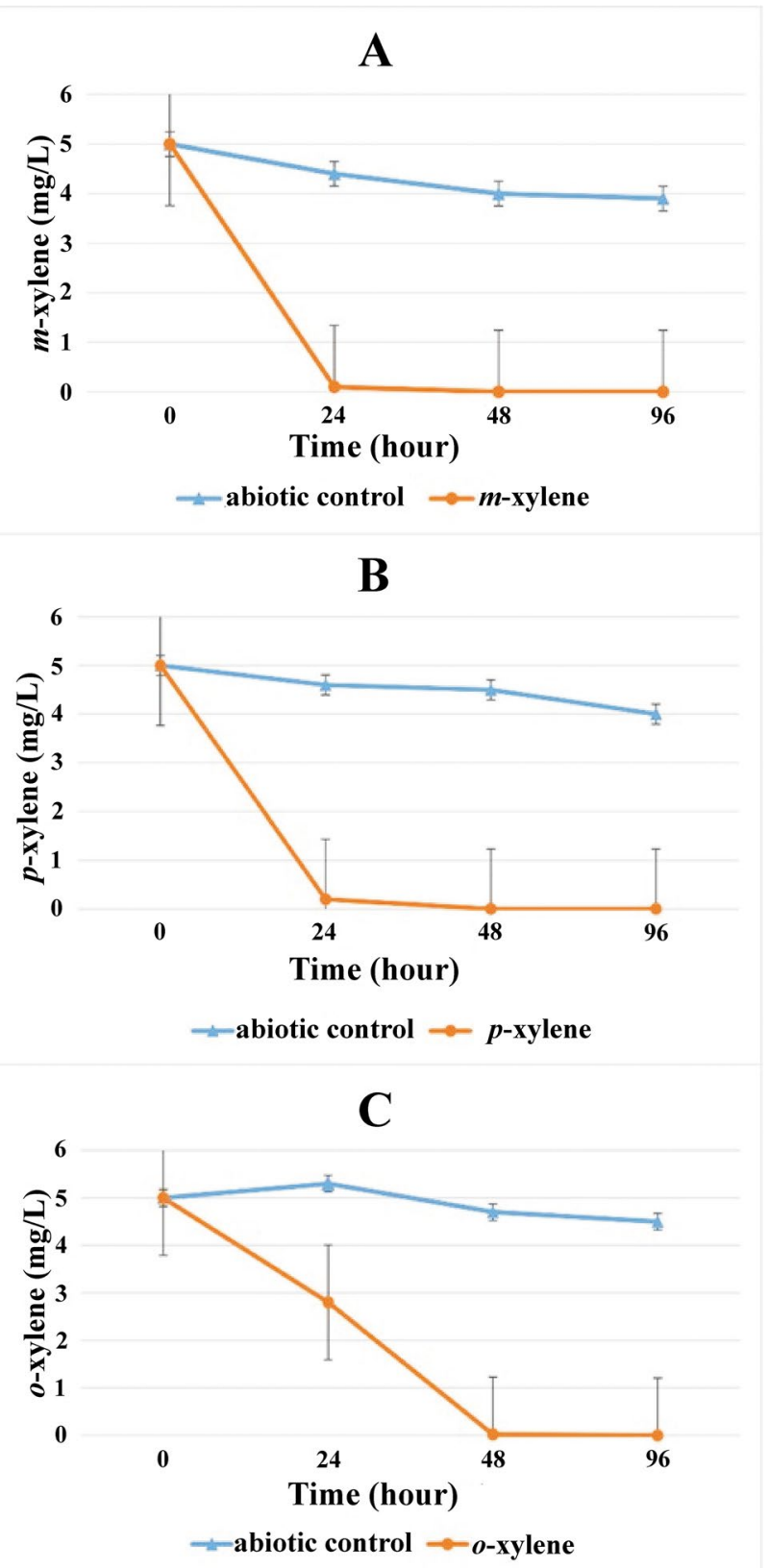

Fig. 1 Degradation process of xylene isomers in the aerobic enrichments containing (A) $m$-xylene, (B) $p$-xylene, and (C) $o$-xylene. Xylene concentrations were measured by GC-MS analysis at the 5th week of enrichment as described in the main text. Means of duplicate enrichments are given (with standard error)

(Fig. 1). Among the enrichments, $m$-xylene degradation was the fastest, where enriched community members took $24 \mathrm{~h}$ to degrade $5 \mathrm{mg} / \mathrm{L}$ concentration of $m$-xylene (Fig. 1, panel A), while $p$-xylene enriched community members took more than $24 \mathrm{~h}$ and less than $48 \mathrm{~h}$ to degrade $5 \mathrm{mg} / \mathrm{L}$ $p$-xylene (Fig. 1, panel B). However, $o$-xylene degradation was a bit slow compared to other enrichments. Community members consumed the same amount of $o$-xylene by $48 \mathrm{~h}$ 
Fig. 2 Bacterial community structure of meta- (M1, M2), para- $(\mathrm{P} 1, \mathrm{P} 2)$, and orthoxylene-degrading $(\mathrm{O} 1, \mathrm{O} 2)$ enrichment cultures as revealed by $16 \mathrm{~S}$ rRNA gene-based T-RFLP

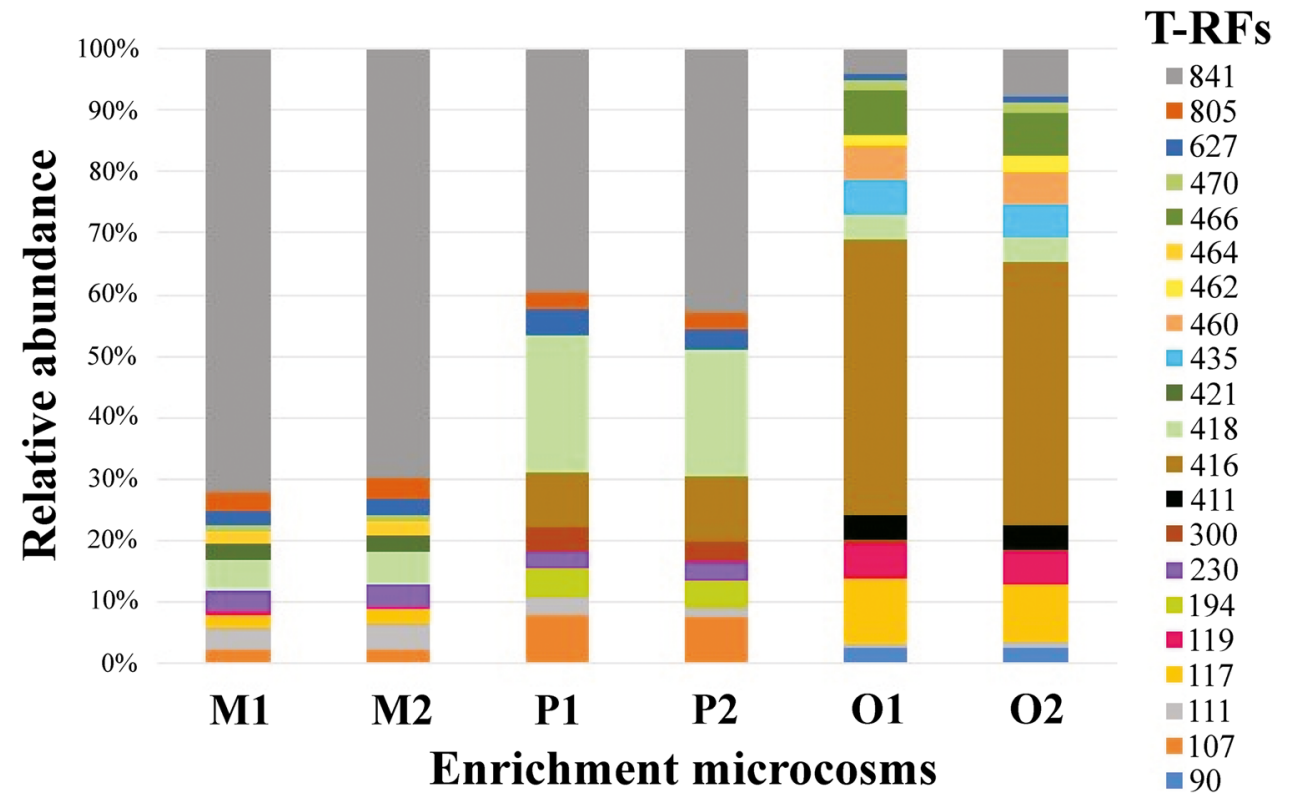

as a carbon source (Fig. 1, panel C). The complete degradation of the added BTEX compounds was confirmed by the change of initial concentration of 5 to $0 \mathrm{mg} / \mathrm{L}$ at the end of the experiment.

\section{Microbial community compositions as revealed by 165 rRNA gene T-RFLP and Illumina 165 rRNA gene amplicon sequencing}

Since T-RFLP analysis has been successfully applied to study microbial communities of various microbial ecosystems (Scala and Kerkhof 2000; Schütte et al. 2008), thus as the first step of community composition evaluation, culture-independent $16 \mathrm{~S}$ rDNA-based T-RFLP analysis was performed using community DNA of the 5th-week enrichments. The primary data of T-RFLP analysis of enrichments and their duplicates revealed the fact about the similarity of the replicates and their community representation.

The bar plot of T-RFLP fingerprints clearly showed that the composition of the bacterial community of $m$-, $p$-, and $o$-xylene-degrading enrichments were distinctly different, and the community composition was relatively similar for replicates (Fig. 2). The most dominant T-RFs in $m$-xylene-degrading enrichments were $841 \mathrm{bp}$ (approximately $72 \%$ ) and 418 bp (approximately 5\%), in p-xylenedegrading enrichments $841 \mathrm{bp}$ (approximately 40\%) and 418 bp (20\%), while in $o$-xylene-degrading enrichments $117 \mathrm{bp}(10 \%)$ and $416 \mathrm{bp}(44 \%)$. The most prominent T-RF that was detectable in all three types of enrichments in different fractions was the $841 \mathrm{bp}$. Major difference creating T-RFs that differentiated the $o$-xylene-degrading enrichments from $m$ - and $p$-xylene-degrading enrichments were $411 \mathrm{bp}, 435 \mathrm{bp}, 460 \mathrm{bp}$, and $466 \mathrm{bp}$. T-RFLP data also suggested that three types of xylene isomer-degrading enrichments differed significantly in the Shannon-H $\left(H^{\prime}\right)$, Simpson_1-D, and Chao-1 diversity indexes (Table S2). The highest Shannon $(H)$ diversity and Chao-1 values were registered in the $o$-xylene-degrading enrichment samples. Contrarily, the lowest Chao-1 values were recorded in $p$-xylene-degrading enrichments, while the Shannon index was observed as lowest in $m$-xylene-degrading enrichments. Considering these results, it could be presumed that $o$-xylene-degrading enrichment communities were the most diverse and species-rich comparing to the others. The Chao1 index was used to estimate the total number of T-RFs in the community. The Chaol values of the six samples from high to low were $\mathrm{O} 1>\mathrm{O} 2>\mathrm{M} 1>\mathrm{M} 2>\mathrm{P} 1>\mathrm{P} 2$, which indicated the total number of similar kinds of T-RFs that is indicative of species. The Shannon index ranged from 1.221 to 2.073, and values of the six samples from high to low were $\mathrm{O} 2>\mathrm{O} 1>\mathrm{P} 1>\mathrm{P} 2>\mathrm{M} 2>\mathrm{M} 1$. At the same time, the Simpson index ranged from 0.468 to 0.787 . The changes in the value of two indexes showed a similar trend, which indicated that the $m$ - and $p$-xylene-degrading enrichment sample in this study contained most of the common T-RF groups. Notably, $o$-xylene-degrading enrichments showed a different trend.

Furthermore, it is interpretable that although $m$-xylenedegrading enrichment showed a higher Chao 1 value still registered a lower Shannon value because the sample had higher species richness but lower evenness. Likewise, the $p$-xylene-degrading enrichment sample had lower species richness but higher evenness. A similar trend could be spotted in the case of Simpson index data also. A higher value of the Simpson index indicates higher diversity. Rare species play a limited role in Simpson's diversity index, 


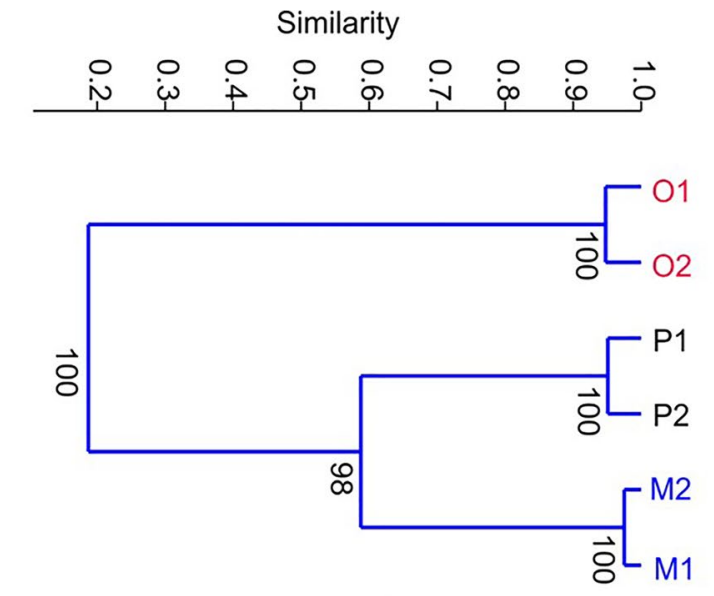

A

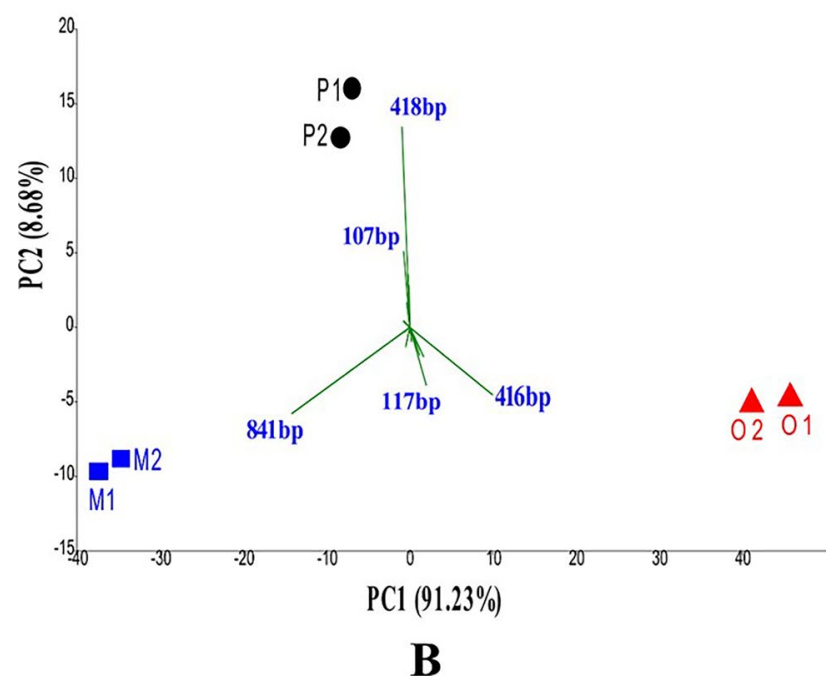

Fig. 3 (A) Cluster analysis of the 16S rRNA gene-based T-RFLP electropherograms of the duplicate enrichment cultures at the 5th week by Bray-Curtis algorithm. (B) Principal component analysis 16S rRNA gene-based T-RFLP electropherograms. M1 and M2, $m$-xylene degrading enrichments; $\mathrm{P} 1$ and $\mathrm{P} 2, p$-xylene-degrading enrichments; $\mathrm{O} 1$ and $\mathrm{O} 2, o$-xylene-degrading enrichments

while common species play a more significant role. The lower the value of Shannon's index is, the lower the diversity is; the lower the value of Simpson's index (range: $0-1$ ) is, the higher the diversity is.

The Bray-Curtis similarity-based cluster analysis of the T-RFLP profiles showed intercorrelation-based hierarchical clustering of beta diversity of enrichment samples, considering T-RF fragment abundances. The UniFrac tree showed that the structure of the bacterial community in the $o$-xylene-degrading enrichments was utterly distinct from the other two types of enrichments where it can be observed that $m$ - and $p$-xylene-degrading enrichments shared similar microbial communities by clustering together in different subgroups, unlike the $o$-xylene-degrading enrichments
(Fig. 3, panel A). Therefore, it is worth mentioning that $o$-xylene-degrading enrichment harbored the most distinct bacterial community. Nevertheless, it was also noticeable that the duplicate enrichments had mostly similar community compositions.

PCA analysis based on $16 \mathrm{~s}$ rDNA T-RFLP profiles revealed the remarkable differences between bacterial community structures of $m-, p$-, and $o$-xylene-degrading enrichment samples. PCA plot pointed out that the replicate samples clustered together in all the cases and showed visible distance in clustering between $m-, p$-, and $o$-xylenedegrading enrichment samples from each other. However, PCA showed that the $o$-xylene-degrading enrichment samples were apparently more distinct microbiologically. In the formation of clusters, the following T-RFs played a significant role: for $o$-xylene $117 \mathrm{bp}$ and $416 \mathrm{bp}$, for $m$-xylene the 841-bp-long T-RF fragment, while for $p$-xylene-degrading enrichments 107-bp and 418-bp T-RFs (Fig. 3, panel B, green vectors).

Presumably, these T-RFs denote bacteria capable of aerobic degradation of xylene isomers as carbon source and became a dominant member of the community. These results confirmed that the replicates are parallel in nature and confer a similar bacterial community. Positive correlations were shown between the first and second components of PC $(\mathrm{PC} 1=91.23 \%, \mathrm{PC} 2=8.68 \%$, respectively $)$.

Based on the T-RFLP results, enrichment samples, namely, M1, P1, and O1, were selected for Illumina 16S rRNA gene amplicon sequencing. To evaluate differences in the alpha diversity of OTUs, rarefaction curve was created for each individual sample showing the number of observed OTUs, defined at a $97 \%$ sequence similarity cutoff in Mothur (Schloss et al. 2009) relative to the number of total identified bacterial rRNA gene sequences (Fig. S1). In general, all the enrichments were rich and diverse. The graph demonstrated that $m$-xylene-degrading microcosm was the enrichment having higher OTU-based richness, whereas $p$-xylene-degrading enrichment showed much less diversity. All of the samples showed OTU-based saturation around 100-120 OTUs.

Finally, a closer, in-depth look at the individual enrichments at class, order, and genus level helped us in understanding the community diversity and composition. At the class level, members of the class Gammaproteobacteria dominated the bacterial community in the majority of the enrichments. Enrichment M1 showed the utmost order-based diversity. Both $\mathrm{M} 1$ and $\mathrm{P} 1$ enrichment communities were dominated by Gammaproteobacteria and Bacteroidia, and the exception was the $\mathrm{O} 1$ enrichment sample where Actinobacteria showed more than $15 \%$ relative abundance in the community, which was making the community different from the other two enrichments (Fig. 4). Order-based analysis revealed that enrichments were harboring primarily 
Fig. 4 Genus-level bacterial community structure of enrichments $\mathrm{M} 1, \mathrm{P} 1$, and $\mathrm{O} 1$ as revealed by Illumina pairedend 16S rRNA gene amplicon sequencing. Only taxa contributing more than $1 \%$ abundance were depicted

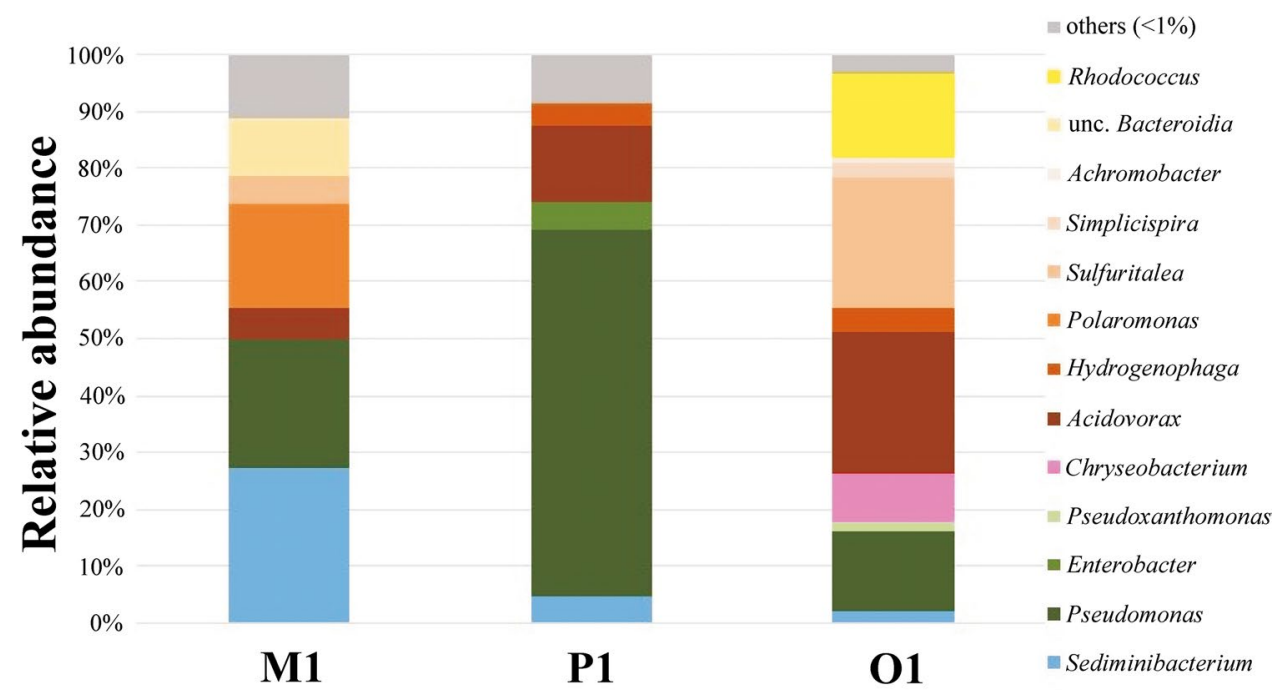

Enrichment microcosms genera belonging to orders Betaproteobacteriales, Pseudomonadales, Chitinophagales, Corynebacteriales, and Bacteroidia.

The bacterial community of the $m$-xylene-degrading enrichment (M1) was dominated by members of the genera Sediminibacterium (27.1\%), Pseudomonas $(22.8 \%)$, and Polaromonas (18.4\%). Whereas in $p$-xylene-degrading enrichment (P1), members of the genus Pseudomonas overwhelmingly dominated the community by showing $64 \%$ relative abundance (Fig. 4). Besides, members of some other genera like Acidovorax (13.2\%), Enterobacter (5.1\%), Sediminibacterium (4.6\%), and Hydrogenophaga (3.9\%) were detectable with prominent abundance as well. However, the $o$-xylene-degrading enrichment (O1) showed an altogether different community structure. Though Pseudomonasrelated bacteria were present in the community but only with $14 \%$ abundance. Acidovorax $(24.9 \%)$ was the most dominant genus along with Sulfuritalea (22.8\%), Rhodococcus (14.6\%), Chryseobacterium (8.4\%), and Hydrogenophaga (4.4\%), making it the most different enrichment based on community diversity in comparison to the two enrichments.

Several among these bacterial genera, such as Acidovorax, Enterobacter, Pseudomonas, Rhodococcus, Sulfuritalea, Simplicispira, Hydrogenophaga, and Polaromonas, have been either found to be present in petroleum-contaminated environments or known to be effective aromatic hydrocarbon degraders (Nishino et al. 2000; Margesin et al. 2003; Jeon et al. 2004; Mattes et al. 2008; Seo et al. 2009; Prince et al. 2010; Varjani and Upasani 2016; Sarkar et al. 2017; Sperfeld et al. 2018; Xu et al. 2020).

Analysis of the Illumina data showed that $m$ - and $p$-xylene-degrading enrichments were primarily predominated by members of the genus Pseudomonas, marginalizing the growth of other genera. The dominant role of
Pseudomonas-related bacteria in aromatic hydrocarbon degradation under strictly aerobic conditions is well known. Thus, these organisms were widely investigated as model organisms to study aerobic BTEX degradation. The $p$-xylene-degrading enrichment, which had a high abundance of sequence reads affiliated with genera Pseudomonas and Acidovorax, enabled us to assume that these bacteria had played a role in the aerobic degradation of p-xylene. Members of the genera Enterobacter and Sediminibacterium (Poi et al. 2018) are frequently observed in petroleum hydrocarbon-contaminated environments, but their role in hydrocarbon degradation is yet not clear (Kaplan and Kitts 2004; Aburto et al. 2009; Singleton et al. 2018). Another major group was Hydrogenophaga present in all of the enrichments, which have been selected to study further to reveal their role in the enrichment community. Likewise, $m$-xylene-degrading enrichment was also dominated with Pseudomonas, Sediminibacterium, and Acidovorax, making the diversity of the enrichment similar to the $p$-xylene-degrading enrichment. The only difference was the introduction of the genus Polaromonas, which is reported to be a genus with potential BTEX degraders (Mattes et al. 2008). Contrarily, the $o$-xylenedegrading bacterial community was considerably different due to the presence of genus Sulfuritalea and Rhodococcus along with Pseudomonas and Acidovorax as the major players in the community. Moreover, the presence of Chryseobacterium, Simplicispira, Pseudoxanthomonas, and Achromobacter in noticeable fractions makes it an interesting and quite different community compared to the other enrichments. Members of the genus Sulfuritalea (Sperfeld et al. 2018), Chryseobacterium (Guo et al. 2008), Simplicispira (Prince et al. 2010), Pseudoxanthomonas (Choi et al. 2013), and Achromobacter (Guo et al. 2008) were 
Table 1 16S rRNA gene-based identification of bacterial strains isolated from the enrichments

\begin{tabular}{|c|c|c|c|c|}
\hline Strain no & Closest relative (type strain) & $\begin{array}{l}\text { Length of } 16 \mathrm{~S} \text { rDNA } \\
\text { analyzed (bp) }\end{array}$ & Similarity $(\%)$ & $\begin{array}{l}\text { Subfamily } \\
\text { I.2.C } C 23 O \\
\text { gene }\end{array}$ \\
\hline \multicolumn{5}{|c|}{$m$-xylene degrading enrichment M1 } \\
\hline D2M1 & Acidovorax delafieldii ATCC 17,505 & 1376 & 100 & + \\
\hline MT3 & Pseudacidovorax intermedius DSM 21,352 & 1420 & 99.93 & + \\
\hline D3M1 & Polaromonas eurypsychrophila CGMCC:1.15322 & 1425 & 99.93 & + \\
\hline D3M2 & Lysobacter sediminicola JCM 18,205 & 1445 & 98.47 & - \\
\hline MW1 & Pseudomonas fluorescens ATCC 13,525 & 1432 & 99.93 & + \\
\hline MT4 & Achromobacter xylosoxidans ATCC 27,061 & 1416 & 99.93 & - \\
\hline \multicolumn{5}{|c|}{$p$-xylene degrading enrichment $\mathbf{P 1}$} \\
\hline $\mathrm{D} 2 \mathrm{P} 1$ & Hydrogenophaga taeniospiralis CCUG 15,921 & 1402 & 99.05 & $+^{*}$ \\
\hline $\mathrm{D} 2 \mathrm{P} 3$ & Hydrogenophaga taeniospiralis CCUG 15,921 & 1418 & 99.15 & + \\
\hline D2P5 & Acidovorax delafieldii ATCC 17,505 & 1428 & 99.93 & + \\
\hline $\mathrm{D} 3 \mathrm{P} 2$ & Mycolicibacterium vanbaalenii DSM 7251 & 1410 & 100 & - \\
\hline P1W2 & Pseudomonas putida ATCC 12,633 & 1428 & 99.86 & + \\
\hline P1W3 & Pseudomonas veronii ATCC 700,272 & 1427 & 100 & - \\
\hline PT4 & Pseudomonas putida ATCC 12,633 & 1441 & 99.86 & + \\
\hline PW1 & Enterobacter roggenkampii DSM 16,690 & 1438 & 99.93 & - \\
\hline \multicolumn{5}{|c|}{$o$-xylene degrading enrichment 01} \\
\hline D201 & Pseudomonas chlororaphis subsp. piscium DSM 21,509 & 1402 & 100 & - \\
\hline D202 & Achromobacter xylosoxidans ATCC 27,061 & 1419 & 99.93 & - \\
\hline D203 & Microbacterium paraoxydans DSM 15,019 & 1412 & 99.93 & - \\
\hline D204 & Rhodococcus imtechensis DSM 45,091 & 1409 & 99.5 & - \\
\hline 0W2 & Pseudomonas chlororaphis subsp. piscium DSM 21,509 & 1432 & 100 & - \\
\hline OW3 & Pseudomonas chlororaphis subsp. piscium DSM 21,509 & 1402 & 100 & - \\
\hline OY1 & Pseudomonas chlororaphis subsp. aureofaciens ATCC 13,985 & 1419 & 99.93 & - \\
\hline
\end{tabular}

* Mixed sequence electropherogram was obtained after Sanger sequencing of the I.2.C C23O amplicon, assuming the presence of more than one I.2.C $\mathrm{C} 23 \mathrm{O}$ genotype in the genome

reported to be present in BTEX enrichments and probably took part in the degradation of BTEX compounds as a carbon source under aerobic conditions. In addition to this, Rhodococcus was the only dominant genus that was not witnessed in other enrichments, assuming it as the leading player for $o$-xylene degradation (Di Canito et al. 2018). Subsequently, this hypothesis was proven in the BTEX degradation experiment as the isolated Rhodococcus strain could effectively degrade $o$-xylene (see below).

Simultaneously, OTU-based bacterial community composition comparison of enrichments using Venn diagrams demonstrated that the $m$-xylene-degrading enrichment was the most diverse community consisting of 57 unique OTUs while $p$ - and $o$-xylene-degrading enrichments had 46 and 45 unique OTUs, respectively. The Venn diagram for the bacterial communities of the three enrichments based on NGS data is presented in Fig. S2. The data also showed that the $m$ - and $p$-xylene-degrading enrichment shared the highest similarity; in contrast, $o$ - and $p$-xylene-degrading enrichments shared the least number of OTUs (only 4). Interestingly, these four shared OTUs were among the least abundant population of sample O1. Additionally, OTUs representing Rhodococcus and Simplicispira were the exclusive abundant genera in $o$-xylene-degrading enrichment. These results might explain the $o$-xylene-degrading enrichment community as a unique community. Furthermore, Hydrogenophaga was one of the abundant overlapping genera present in all of the enrichments in different proportions.

\section{Isolates and their BTEX degradation capability}

Following classical microbiological techniques, bacterial strains were isolated on R2A agar plates from enrichments that have also been analyzed by Illumina 16S rRNA gene amplicon sequencing. Based on different colony morphology and growth pattern total number of 21 strains have been isolated, among which six isolates originated from $m$-xylenedegrading enrichment, eight isolates from $p$-xylene-degrading enrichment, and seven isolates from $o$-xylene-degrading enrichment (Table 1).

Strains isolated from the $m$-xylene-degrading enrichment (M1) belonged to the genera of Acidovorax, 
Pseudacidovorax, Polaromonas, Lysobacter, Pseudomonas, and Achromobacter. Amid those strains, Acidovorax, Pseudacidovorax, Polaromonas, and Pseudomonas possessed subfamily I.2.C-type $C 23 O$ gene, which was sequenced further to study functional gene diversity in the isolated community members. Among those strains, Polaromonas and Pseudacidovorax were selected for further degradation study because of limited available knowledge on their role as potential xylene degraders. Unfortunately, the Polaromonas strain was lost during subculturing. Hence, BTEX degradation ability of Pseudacidovorax was only checked and observed that it could degrade $5 \mathrm{mg} / \mathrm{L}$ concentration of benzene and ethylbenzene in approximately $48 \mathrm{~h}$ (data not shown). In contrast, it was unable to degrade toluene and any isomer of xylene.

Overall, eight strains were isolated from the $p$-xylenedegrading enrichment (P1), which were members of the genera Hydrogenophaga, Acidovorax, Mycolicibacterium, Pseudomonas, and Enterobacter. The screening of subfamily I.2.C-type $C 23 O$ gene showed that Hydrogenophaga, Acidovorax, and Pseudomonas strains harbored such a gene. Among these strains, two Hydrogenophaga strains (sharing identical 16S rRNA genes) showed limited similarity with their closest relative. The presence of subfamily I.2.Ctype $\mathrm{C} 23 \mathrm{O}$ gene made it a potential candidate of interest as information about their biodegradation potential is not so widely available, also not yet considered as a credible candidate for bioremediation. Hence, the biodegradation ability of both Hydrogenophaga strains D2P1 and D2P3 (both showing $99.1 \%$ similarity with type strain Hydrogenophaga taeniospiralis CCUG $15921^{\mathrm{T}}$ ) were studied extensively. Surprisingly, although these two strains belonged to the same species they showed different degradation potential towards different BTEX compounds. In the case of Hydrogenophaga sp. strain D2P1 degradability for $m$-, $p$-xylene and benzene was shown earlier (Banerjee et al. 2021). During the present study it was observed that strain D2P1 was capable of degrading $5 \mathrm{mg} / \mathrm{L}$ concentration of $m$-xylene within $24 \mathrm{~h}$ and $p$-xylene within approximately $48 \mathrm{~h}$ of incubation at $28{ }^{\circ} \mathrm{C}$ and degradation of same concentration of benzene within around $120 \mathrm{~h}$ under similar conditions (Fig. 5). In contrast, Hydrogenophaga sp. strain D2P3 showed utilization of completely different BTEX compounds as carbon source. Strain D2P3 was able to degrade $5 \mathrm{mg} / \mathrm{L}$ concentration of toluene around $48 \mathrm{~h}$, benzene within $96 \mathrm{~h}$, and $o$-xylene in more than 96-h incubation at $28{ }^{\circ} \mathrm{C}$ (Fig. 6).

The lowest diversity of isolates was observable in case of the $o$-xylene-degrading enrichment $\mathrm{O} 1$. The seven isolates obtained from this enrichment belonged to four genera. Besides, none of them harbored subfamily I.2.C-type $\mathrm{C} 23 \mathrm{O}$ gene. Although the $o$-xylene degradation ability of Rhodococcus (Charniauskaya et al. 2018) is well known still, the degradation potential of the isolated Rhodococcus

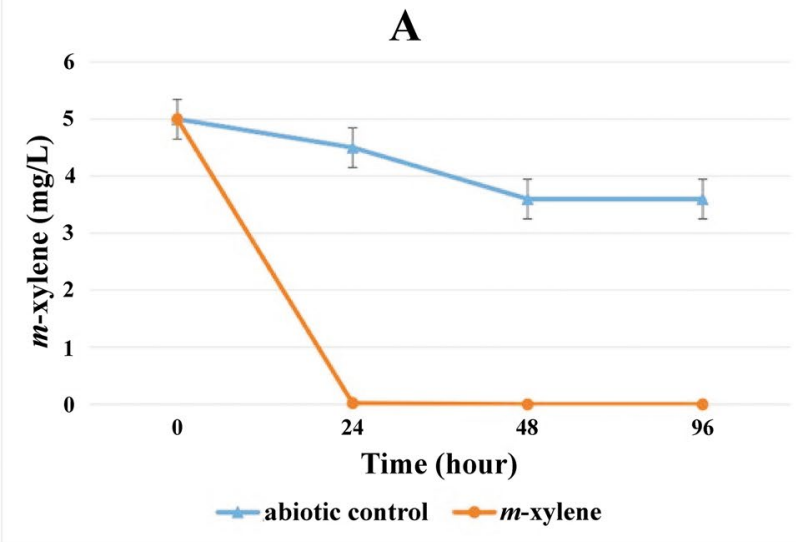

B
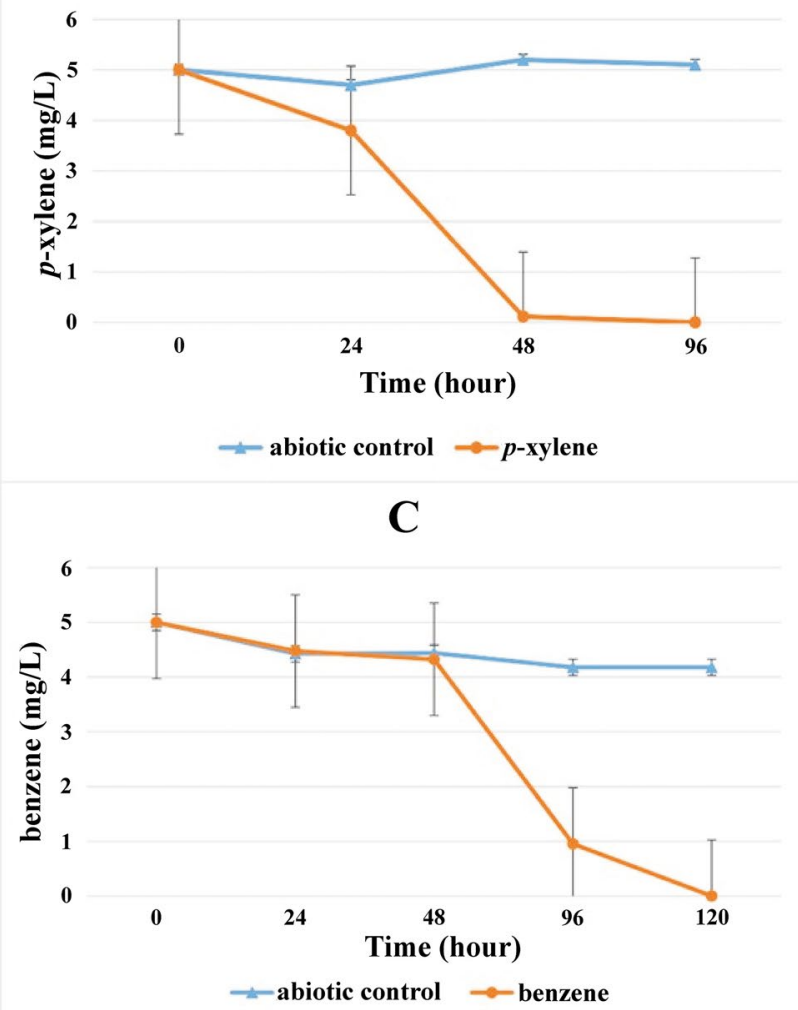

Fig. 5 Aerobic degradation of (A) $m$-xylene, (B) p-xylene, and (C) benzene by Hydrogenophaga sp. strain D2P1. Concentrations were determined by GC-MS analysis as described in the main text. The averages of triplicate experiments \pm standard errors of the means, indicated by error bars, are shown

imtechensis strain $\mathrm{D} 2 \mathrm{O} 4$ was assessed, which led us to the observation that it could degrade $o$-xylene, toluene, and benzene (data are not shown), which explains its presence in the $o$-xylene-degrading enrichment community as a key player of $o$-xylene utilization. Alongwith that two strains belonging to genus Pseudomonas, Pseudomonas chlororaphis subsp. piscium and Pseudomonas chlororaphis subsp. aureofaciens were also investigated to assign their role in 

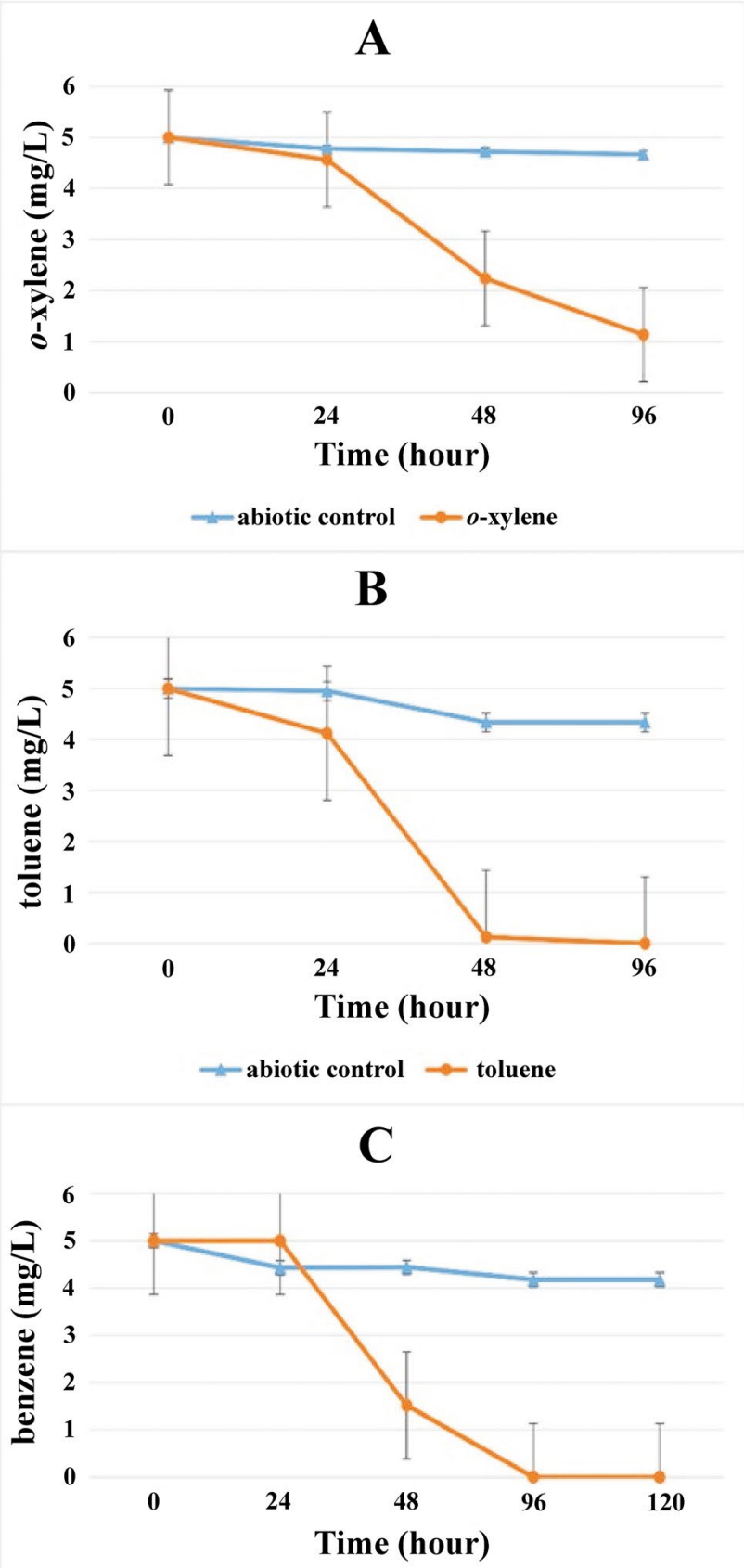

$\leadsto$ abiotic control $\multimap$ benzene

Fig. 6 Aerobic degradation of (A) o-xylene, (B) toluene, and (C) benzene by Hydrogenophaga sp. strain D2P3. Concentrations were determined by GC-MS analysis as described in the main text. The averages of triplicate experiments \pm standard errors of the means, indicated by error bars, are shown

the $o$-xylene-degradating community, but unfortunately they showed inability to degrade xylenes as carbon source.

\section{Comparative whole-genome analysis of two Hydrogenophaga sp. strains D2P1 ${ }^{\top}$ and D2P3, with particular emphasis on aromatic hydrocarbon-degrading ability}

Among the isolates, the two Hydrogenophaga strains, D2P1 and $\mathrm{D} 2 \mathrm{P} 3$, were the most interesting for us, since they were able to degrade at least one of the xylene isomers and possessed subfamily I.2.C-type $C 23 O$ genes. The two strains shared identical 16S rRNA genes, but Sanger sequencing revealed that they encode entirely different subfamily I.2.C-type $C 23 O$ genotypes. Moreover, based on the Sanger sequencing result, it could be assumed that strain D2P1 harbors more than one genotype of the corresponding $\mathrm{C} 23 \mathrm{O}$ gene, since mixed sequencing electrophoretogram was obtained. Based on the 16S rRNA gene similarity, strains D2P1 and D2P3 were closely related to $H$. taeniospiralis ( $\sim 99.1 \%$ homology), and they shared identical 16S rRNA gene sequence with Hydrogenophaga sp. strain Rs71, which was isolated by Fahy et al. (2006) earlier as a benzenedegrading bacterium. Moreover, it was shown that strain Rs71 was able to degrade toluene, $m$-, and $p$-xylene as well (Fahy et al. 2008) similarly to strain D2P1. By the time of writing, strain D2P1 was validly described as type strain of the new species Hydrogenophaga aromaticivorans, and the analysis of the whole genome of strain $\mathrm{D} 2 \mathrm{P} 1^{\mathrm{T}}$ revealed that it has three different subfamily I.2.C-type $C 23 O$ genes (Banerjee et al. 2021). Besides, a large gene cluster ( 28 $\mathrm{kbp}$ ) was identified, which encoded all of the genes (e.g., xylene monooxygenase and benzoate 1,2-dioxygenase) required for the transformation of $p$ - and $m$-xylene to 3and 4-methylcatechol, respectively (Banerjee et al. 2021). This cluster contained one of the subfamily I.2.C-type C23O genes (locus tag F3K02_21385), and it was identified during this study as part of a genomic island, based on the SIGI-HMM algorithm of IslandViewer 4. Since strain D2P3 was not able to utilize $p$ - and $m$-xylene, but could use $o$-xylene as sole source of carbon and energy, we sequenced its whole genome as well. Subsequently, the two genomes were aligned to each other and analyzed. The $\mathrm{dDDH}$ value between strain $\mathrm{D} 2 \mathrm{P} 1^{\mathrm{T}}$ and $\mathrm{D} 2 \mathrm{P} 3$ was $79.7 \%$, while the OrthoANI value was $97.6 \%$, which clearly indicated that they belong to the same genomic species. Besides, they had highly similar genome size (5.63 and $5.80 \mathrm{Mb}$, respectively). Alignment of the genome sequences revealed that strain D2P3 lacks the xylene-degradation gene cluster, which was observable in case of strain $\mathrm{D} 2 \mathrm{P} 1^{\mathrm{T}}$. On the other hand, both strains harbor a phenol degradation gene cluster, encoding a multicomponent phenol hydroxylase $(\mathrm{mPH})$ together with a complete meta-cleavage pathway. However, these gene clusters are different in structure, and the corresponding genes show only $\sim 80-90 \%$ sequence similarity to each other (Fig. 7). Still, this difference can be the key to understand 
Fig. 7 Physical map of the phenol degradation gene clusters of Hydrogenophaga sp. strains $\mathrm{D} 2 \mathrm{P} 1^{\mathrm{T}}$ and $\mathrm{D} 2 \mathrm{P} 3$
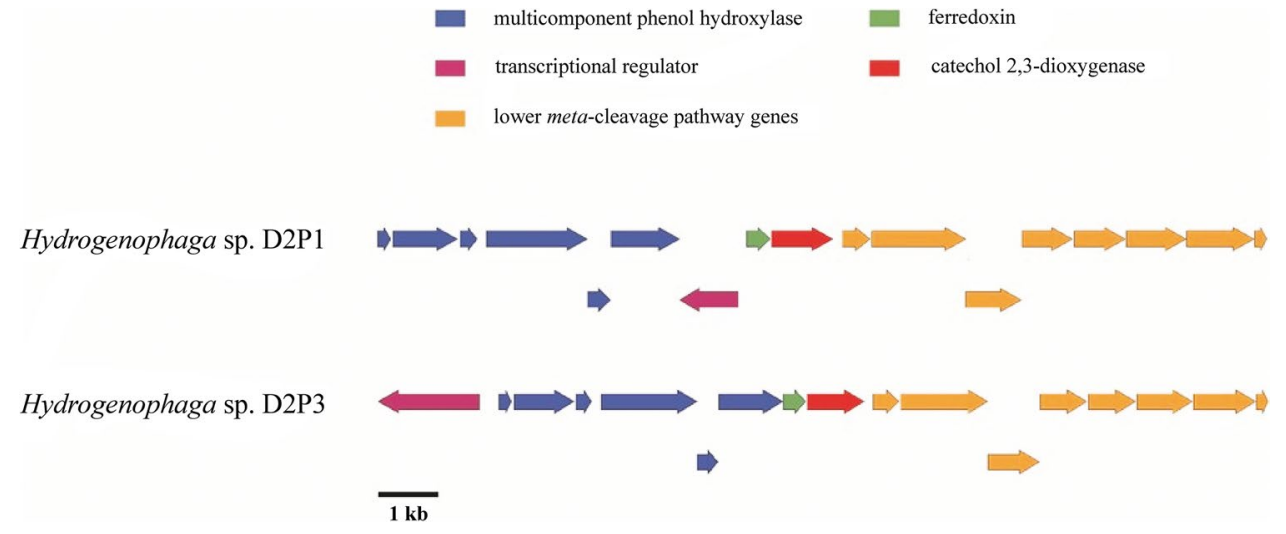

the different xylene-degrading ability of strains $\mathrm{D} 2 \mathrm{P} 1^{\mathrm{T}}$ and D2P3. It was observed in case of Pseudomonas stutzeri strain OX1, which is a prominent toluene and $o$-xylenedegrading bacterium, that a phenol degradation gene cluster plays crucial role in its $o$-xylene-degrading ability. The structure of this phenol degradation operon shows similarity to that of was observed in strain D2P3. Both operons are regulated by a $\sigma^{54}$-interacting transcriptional regulator and the organization of the $\mathrm{mPH}$ and lower meta-cleavage genes is similar (at least at the known parts of the operon in case of $P$. stutzeri strain OX1). The $\mathrm{C} 23 \mathrm{O}$ enzyme coded in this operon of $P$. stutzeri strain OX1 can cleave 3,4-dimethylcatechol, but cannot cleave 3,5- and 3,6-dimethylcatechols. Consequently, strain OX1 can degrade $o$-xylene, but cannot grow on $m$ - and $p$-xylenes (Arenghi et al. 2001). A similar scenario can be assumed in the case of Hydrogenophaga sp. strain D2P3. Due to the presence of a single transcriptional regulator it can also be speculated that the whole phenoldegradation gene cluster of this strain is transcribed as an extraordinarily large operon, similarly as in Pseudomonas sp. strain CF600 (Shingler, 1996). However, it is still a question how the $o$-xylene is converted into 3,4-dimethylphenol, since toluene- $o$-xylene monooxygenase was not found in the genome of strain D2P3. One possible explanation is that the $\mathrm{mPH}$ is responsible for both the hydroxylation of $o$-xylene and the subsequent hydroxylation of 3,4-dimethylphenol to 3,4-dimethylcatechol. Nevertheless, transcriptomic analysis will be necessary to answer this question. In the case of strain $\mathrm{D} 2 \mathrm{P} 1^{\mathrm{T}}$ a LysR-type transcriptional regulator gene was found wedged between the $\mathrm{mPH}$ and the ferredoxin gene (Fig. 7). Besides, no $\sigma^{54}$-interacting transcriptional regulator gene was found upstream of the $\mathrm{mPH}$. Instead, an orf encoding an IS5 family transposase was found in the corresponding position, hinting at the possibility that this gene cluster was acquired through horizontal gene transfer (HGT) by strain $\mathrm{D} 2 \mathrm{P} 1^{\mathrm{T}}$. Moreover, it can also be speculated that this gene cluster functions only partially, since the $\mathrm{mPH}$ lacks its own transcriptional regulator.

\section{Conclusion}

Based on all above it can be concluded that the microbial community at the Siklos BTEX-contaminated site of Hungary has the metabolic potential to aerobically degrade all isomers of xylene. Polyphasic analysis of the enrichments revealed that distinctly different bacterial communities played role in the degradation of the different xylene isomers. Still, members of the genera Pseudomonas and Acidovorax were abundant community members in all of the enrichments, while bacteria belonging to the genera Rhododoccus and Chryseobacterium were key players only in the $o$-xylene-degrading enrichment cultures. It was confirmed by the results that members of the genus Hydrogenophaga, harboring subfamily I.2.C-type $C 23 O$ genes, can be prominent xylene-degraders, and some strains can even acquire $o$-xylene-degrading ability as well. In connection with this, the whole-genome analysis of two $H$. aromaticivorans strains revealed that different subpopulations of the same species with different xylene-degrading capabilities may coexist in the same environment. Our findings also shed light on the fact that even three or more subfamily I.2.C-type $C 23 O$ genotypes can be linked to one single species of the degrader community. Consequently, the high diversity of subfamily I.2.C-type $C 23 O$ genes does not necessarily mean high degrader diversity in a contaminated environment.

Supplementary Information The online version contains supplementary material available at https://doi.org/10.1007/s11356-021-18300-w.

Author contribution SB: enrichment experiments and strain isolation (lead), NGS analyses (equal), writing — original draft (lead), writing - review and editing (equal); AB: NGS analyses (equal); PH: groundwater sampling and on-site analysis (lead); BK: writing - review and editing (equal); NA: strain isolation (equal); AT: conceptualization (lead), writing — review and editing (equal).

Funding Open access funding provided by Hungarian University of Agriculture and Life Sciences. This research was supported by the Ministry of Innovation and Technology of Hungary within the framework 
of the Thematic Excellence Programme 2020, Institutional Excellence Subprogramme (TKP2020-IKA-12). AT was supported by the "OTKA" Young Researcher Excellence Programme of the National Research, Development and Innovation Office - NKFIH (grant agreement no. FK 134439). SB received financial support from the Tempus Public Foundation (Stipendium Hungaricum Scholarship Programme) by the Ministry of Human Capacities of Hungary.

Availability of data and materials Whole-genome sequence data are available under the BioPoject accession number PRJNA565673. 16S rRNA gene amplicon sequencing data are available under the BioProject accession number PRJNA704261. Other datasets used and analyzed during the current study are available from the corresponding author on reasonable request.

\section{Declarations}

Ethics approval and consent to participate Not applicable.

Consent for publication Not applicable.

Conflict of interest The authors declare no competing interests.

Open Access This article is licensed under a Creative Commons Attribution 4.0 International License, which permits use, sharing, adaptation, distribution and reproduction in any medium or format, as long as you give appropriate credit to the original author(s) and the source, provide a link to the Creative Commons licence, and indicate if changes were made. The images or other third party material in this article are included in the article's Creative Commons licence, unless indicated otherwise in a credit line to the material. If material is not included in the article's Creative Commons licence and your intended use is not permitted by statutory regulation or exceeds the permitted use, you will need to obtain permission directly from the copyright holder. To view a copy of this licence, visit http://creativecommons.org/licenses/by/4.0/.

\section{References}

Aburto A, Fahy A, Coulon F, et al (2009) Mixed aerobic and anaerobic microbial communities in benzene-contaminated groundwater. $\mathbf{J}$ Appl Microbiol 106https://doi.org/10.1111/j.1365-2672.2008. 04005. $\mathrm{x}$

Alrumman SA, Standing DB, Paton GI (2015) Effects of hydrocarbon contamination on soil microbial community and enzyme activity. J King Saud Univ - Sci 27https://doi.org/10.1016/j.jksus.2014. 10.001

Andreoni V, Gianfreda L (2007) Bioremediation and monitoring of aromatic-polluted habitats. Appl. Microbiol. Biotechnol. 76

Arenghi FLG, Berlanda D, Galli E, et al (2001) Organization and regulation of meta cleavage pathway genes for toluene and o-xylene derivative degradation in Pseudomonas stutzeri OX1. Appl Environ Microbiol 67https://doi.org/10.1128/AEM.67.7.3304-3308. 2001

Atlas RM, Hazen TC (2011) Oil biodegradation and bioremediation: a tale of the two worst spills in U.S. history. Environ Sci Technol 45:. https://doi.org/10.1021/es2013227

Banerjee S, Táncsics A, Tóth E, et al (2021) Hydrogenophaga aromaticivorans sp. nov., isolated from a para-xylene-degrading enrichment culture, capable of degrading benzene, meta-and para-xylene. Int J Syst Evol Microbiol 71:. https://doi.org/10. 1099/ijsem.0.004743
Bateman A (2019) UniProt: a worldwide hub of protein knowledge. Nucleic Acids Res 47https://doi.org/10.1093/nar/gky1049

Benedek T, Szentgyorgyi F, Szabo I et al (2018) Aerobic and oxygen-limited enrichment of BTEX-degrading biofilm bacteria: dominance of Malikia versus Acidovorax species. Environ Sci Pollut Res Int 25:32178-32195. https://doi.org/10.1007/ s11356-018-3096-6

Benedek T, Táncsics A, Szabó I, et al (2016) Polyphasic analysis of an Azoarcus-Leptothrix-dominated bacterial biofilm developed on stainless steel surface in a gasoline-contaminated hypoxic groundwater. Environ Sci Pollut Res 23https://doi.org/10.1007/ s11356-016-6128-0

Bertelli C, Laird MR, Williams KP, et al (2017) IslandViewer 4: expanded prediction of genomic islands for larger-scale datasets. Nucleic Acids Res 45https://doi.org/10.1093/nar/gkx343

Boonsaner M, Borrirukwisitsak S, Boonsaner A (2011) Phytoremediation of BTEX contaminated soil by Canna $\times$ generalis. Ecotoxicol Environ Saf 74https://doi.org/10.1016/j.ecoenv.2011.04.011

Borsodi AK, Aszalós JM, Bihari P et al (2019) Anaerobacillus alkaliphilus sp. nov., a novel alkaliphilic and moderately halophilic bacterium. Int J Syst Evol Microbiol 69:631-637. https://doi.org/ 10.1099/ijsem.0.003128

Di Canito A, Zampolli J, Orro A, et al (2018) Genome-based analysis for the identification of genes involved in o-xylene degradation in Rhodococcus opacus R7. BMC Genomics 19https://doi.org/ 10.1186/s12864-018-4965-6

Caspi R, Altman T, Billington R, et al (2014) The MetaCyc database of metabolic pathways and enzymes and the BioCyc collection of Pathway/Genome Databases. Nucleic Acids Res 42https://doi. org/10.1093/nar/gkt1103

Charniauskaya MI, Bukliarevich AA, Delegan YA, et al (2018) Biodiversity of hydrocarbon-oxidizing soil bacteria from various climatic zones. Microbiol (Russian Fed 87:. https://doi.org/10.1134/ S0026261718050065

Choi EJ, Jin HM, Lee SH, et al (2013) Comparative genomic analysis and benzene, toluene, ethylbenzene, and o-, m-, and p-xylene (BTEX) degradation pathways of Pseudoxanthomonas spadix BD-a59. Appl Environ Microbiol 79https://doi.org/10.1128/AEM. 02809-12

Das N, Chandran P (2011) Microbial degradation of petroleum hydrocarbon contaminants: an overview. Biotechnol Res Int 2011https:// doi.org/10.4061/2011/941810

Delhoménie MC, Bibeau L, Gendron J, Brzezinski R (2003) Degradation of toluene, xylene, and trimethylbenzene vapors by biofiltration: a comparison. J Air Waste Manag Assoc 53:. https://doi.org/ 10.1080/10473289.2003.10466137

Dolfing J, Zeyer J, Binder-Eicher P, Schwarzenbach RP (1990) Isolation and characterization of a bacterium that mineralizes toluene in the absence of molecular oxygen. Arch Microbiol 154https:// doi.org/10.1007/BF00276528

Edgar RC, Haas BJ, Clemente JC, et al (2011) UCHIME improves sensitivity and speed of chimera detection. Bioinformatics $27 \mathrm{https} / / /$ doi.org/10.1093/bioinformatics/btr381

Fahy A, McGenity TJ, Timmis KN, Ball AS (2006) Heterogeneous aerobic benzene-degrading communities in oxygen-depleted groundwaters. FEMS Microbiol Ecol 58:260-270. https://doi. org/10.1111/j.1574-6941.2006.00162.x

Fahy A, Ball AS, Lethbridge G et al (2008) Isolation of alkali-tolerant benzene-degrading bacteria from a contaminated aquifer. Lett Appl Microbiol 47:60-66. https://doi.org/10.1111/j.1472-765X. 2008.02386.x

Farkas M, Szoboszlay S, Benedek T, et al (2017) Enrichment of dissimilatory $\mathrm{Fe}(\mathrm{III})$-reducing bacteria from groundwater of the Siklos BTEX-contaminated site (Hungary). Folia Microbiol (Praha) 62https://doi.org/10.1007/s12223-016-0473-8 
Fries MR, Zhou J, Chee-Sanford J, Tiedje JM (1994) Isolation, characterization, and distribution of denitrifying toluene degraders from a variety of habitats. Appl Environ Microbiol 60https://doi.org/ 10.1128/aem.60.8.2802-2810.1994

Guo W, Li D, Tao Y, et al (2008) Isolation and description of a stable carbazole-degrading microbial consortium consisting of Chryseobacterium sp. NCY and Achromobacter sp. NCW. Curr Microbiol 57:. /https://doi.org/10.1007/s00284-008-9185-x

Hammer Ø, Harper DAT, Ryan PD (2001) Past: Paleontological statistics software package for education and data analysis. Palaeontol Electron 4:

Harms G, Zengler K, Rabus R, et al (1999) Anaerobic oxidation of o-xylene, $\mathrm{m}$-xylene, and homologous alkylbenzenes by new types of sulfate-reducing bacteria. Appl Environ Microbiol 65https:// doi.org/10.1128/aem.65.3.999-1004.1999

Higashioka Y, Kojima H, Fukui M (2012) Isolation and characterization of novel sulfate-reducing bacterium capable of anaerobic degradation of p-xylene. Microbes Environ 27https://doi.org/10. 1264/jsme2.ME11357

Jahn MK, Haderlein SB, Meckenstock RU (2005) Anaerobic degradation of benzene, toluene, ethylbenzene, and o-xylene in sedimentfree iron-reducing enrichment cultures. Appl Environ Microbiol 71https://doi.org/10.1128/AEM.71.6.3355-3358.2005

Jechalke S, Franchini AG, Bastida F et al (2013) Analysis of structure, function, and activity of a benzene-degrading microbial community. FEMS Microbiol Ecol 85:14-26. https://doi.org/10.1111/ 1574-6941.12090

Jeon CO, Park W, Ghiorse WC, Madsen EL (2004) Polaromonas naphthalenivorans sp. nov., a naphthalene-degrading bacterium from naphthalene-contaminated sediment. Int J Syst Evol Microbiol 54:. https://doi.org/10.1099/ijs.0.02636-0

Kandyala R, Raghavendra SP, Rajasekharan S (2010) Xylene: an overview of its health hazards and preventive measures. J Oral Maxillofac Pathol 14https://doi.org/10.4103/0973-029x.64299

Kanehisa M, Goto S (2000) KEGG: Kyoto Encyclopedia of Genes and Genomes. Nucleic Acids Res. 28

Kao CM, Wang CC (2000) Control of BTEX migration by intrinsic bioremediation at a gasoline spill site. Water Res 34https://doi. org/10.1016/S0043-1354(00)00070-1

Kaplan CW, Kitts CL (2004) Bacterial succession in a petroleum land treatment unit. Appl Environ Microbiol 70https://doi.org/10.1128/ AEM.70.3.1777-1786.2004

Kim M, Oh H-S, Park S-C, Chun J (2014) Towards a taxonomic coherence between average nucleotide identity and 16S rRNA gene sequence similarity for species demarcation of prokaryotes. Int J Syst Evol Microbiol 64:346-351. https://doi.org/10.1099/ijs.0. 059774-0

Klindworth A, Pruesse E, Schweer T, et al (2013) Evaluation of general 16 S ribosomal RNA gene PCR primers for classical and nextgeneration sequencing-based diversity studies. Nucleic Acids Res 41https://doi.org/10.1093/nar/gks808

Kovalick WW (1992) Trends in innovative treatment technologies at contaminated sites. In: Water Science and Technology

Kozich JJ, Westcott SL, Baxter NT, et al (2013) Development of a dual-index sequencing strategy and curation pipeline for analyzing amplicon sequence data on the miseq Illumina sequencing platform. Appl Environ Microbiol 79https://doi.org/10.1128/AEM. 01043-13

Kunin V, Engelbrektson A, Ochman H, Hugenholtz P (2010) Wrinkles in the rare biosphere: pyrosequencing errors can lead to artificial inflation of diversity estimates. Environ Microbiol 12https://doi. org/10.1111/j.1462-2920.2009.02051.x

Lee I, Ouk Kim Y, Park S-C, Chun J (2016) OrthoANI: An improved algorithm and software for calculating average nucleotide identity. Int J Syst Evol Microbiol 66:1100-1103. https://doi.org/10.1099/ ijsem.0.000760
Lin C, Gan L, Chen ZL (2010) Biodegradation of naphthalene by strain Bacillus fusiformis (BFN). J Hazard Mater 182https://doi.org/10. 1016/j.jhazmat.2010.06.101

Margesin R, Labbé D, Schinner F, et al (2003) Characterization of hydrocarbon-degrading microbial populations in contaminated and pristine Alpine soils. Appl Environ Microbiol 69https://doi. org/10.1128/AEM.69.6.3085-3092.2003

Marshall AG, Rodgers RP (2008) Petroleomics: chemistry of the underworld. Proc Natl Acad Sci U S A 105https://doi.org/10. 1073/pnas.0805069105

Mattes TE, Alexander AK, Richardson PM, et al (2008) The genome of Polaromonas sp. strain JS666: insights into the evolution of a hydrocarbon- and xenobiotic-degrading bacterium, and features of relevance to biotechnology. Appl Environ Microbiol 74:. https:// doi.org/10.1128/AEM.00197-08

Mazzeo DEC, Matsumoto ST, Levy CE et al (2013) Application of micronucleus test and comet assay to evaluate BTEX biodegradation. Chemosphere 90:1030-1036. https://doi.org/10.1016/j. chemosphere.2012.08.012

Meier-Kolthoff JP, Auch AF, Klenk H-P, Göker M (2013) Genome sequence-based species delimitation with confidence intervals and improved distance functions. BMC Bioinformatics 14:60. https:// doi.org/10.1186/1471-2105-14-60

Morasch B, Schink B, Tebbe CC, Meckenstock RU (2004) Degradation of o-xylene and m-xylene by a novel sulfate-reducer belonging to the genus Desulfotomaculum. Arch Microbiol 181https://doi.org/ 10.1007/s00203-004-0672-6

Nishino SF, Paoli GC, Spain JC (2000) Aerobic degradation of dinitrotoluenes and pathway for bacterial degradation of 2,6-dinitrotoluene. Appl Environ Microbiol 66https://doi.org/10.1128/AEM. 66.5.2139-2147.2000

Noguchi M, Kurisu F, Kasuga I, Furumai H (2014) Time-resolved DNA stable isotope probing links Desulfobacterales- and Coriobacteriaceae-related bacteria to anaerobic degradation of benzene under methanogenic conditions. Microbes Environ 29https://doi. org/10.1264/jsme2.ME13104

Nurk S, Bankevich A, Antipov D, et al (2013) Assembling genomes and mini-metagenomes from highly chimeric reads. In: Lecture Notes in Computer Science (including subseries Lecture Notes in Artificial Intelligence and Lecture Notes in Bioinformatics)

Poi G, Shahsavari E, Aburto-Medina A, et al (2018) Large scale treatment of total petroleum-hydrocarbon contaminated groundwater using bioaugmentation. J Environ Manage 214https://doi.org/10. 1016/j.jenvman.2018.02.079

Prince RC, Gramain A, McGenity TJ (2010) Prokaryotic hydrocarbon degraders

Quast C, Pruesse E, Yilmaz P, et al (2013) The SILVA ribosomal RNA gene database project: improved data processing and web-based tools. Nucleic Acids Res 41https://doi.org/10.1093/nar/gks1219

Rabus R, Widdel F (1995) Anaerobic degradation of ethylbenzene and other aromatic hydrocarbons by new denitrifying bacteria. Arch Microbiol 163https://doi.org/10.1007/BF00381782

Reardon KF, Mosteller DC, Bull Rogers JD (2000) Biodegradation kinetics of benzene, toluene, and phenol as single and mixed substrates for Pseudomonas putida F1. Biotechnol Bioeng 69 https://doi.org/10.1002/1097-0290(20000820)69:4<385::AIDBIT5>3.0.CO;2-Q

Robledo-Ortíz JR, Ramírez-Arreola DE, Pérez-Fonseca AA, et al (2011) Benzene, toluene, and o-xylene degradation by free and immobilized $P$. putida $\mathrm{F} 1$ of postconsumer agave-fiber/polymer foamed composites. Int Biodeterior Biodegrad 65:. https://doi.org/ 10.1016/j.ibiod.2010.12.011

Sarkar P, Roy A, Pal S, et al (2017) Enrichment and characterization of hydrocarbon-degrading bacteria from petroleum refinery waste as potent bioaugmentation agent for in situ bioremediation. Bioresour Technol 242https://doi.org/10.1016/j.biortech.2017.05.010 
Scala DJ, Kerkhof LJ (2000) Horizontal heterogeneity of denitrifying bacterial communities in marine sediments by terminal restriction fragment length polymorphism analysis. Appl Environ Microbiol 66https://doi.org/10.1128/AEM.66.5.1980-1986.2000

Schloss PD, Westcott SL, Ryabin T, et al (2009) Introducing mothur: open-source, platform-independent, community-supported software for describing and comparing microbial communities. Appl Environ Microbiol 75https://doi.org/10.1128/AEM.01541-09

Schütte UME, Abdo Z, Bent SJ et al (2008) Advances in the use of terminal restriction fragment length polymorphism (T-RFLP) analysis of $16 \mathrm{~S}$ rRNA genes to characterize microbial communities. Appl Microbiol Biotechnol 80:365-380. https://doi.org/10. 1007/s00253-008-1565-4

Seo JS, Keum YS, Li QX (2009) Bacterial degradation of aromatic compounds. Int. J. Environ. Res. Public Health 6

Shingler V (1996) Metabolic and regulatory checkpoints in phenol degradation by Pseudomonas sp. CF600 edited by Nakazawa T., Furukawa K., Haas D., Silver S. Washington, In Molecular Biology of Pseudomonas pp. Am Soc Microbiol In Molecul:153-154

Silva IS, Grossman M, Durrant LR (2009) Degradation of polycyclic aromatic hydrocarbons (2-7 rings) under microaerobic and verylow-oxygen conditions by soil fungi. Int Biodeterior Biodegrad 63:224-229. https://doi.org/10.1016/j.ibiod.2008.09.008

Singleton DR, Lee J, Dickey AN, et al (2018) Polyphasic characterization of four soil-derived phenanthrene-degrading Acidovorax strains and proposal of Acidovorax carolinensis sp. nov. Syst Appl Microbiol 41:. https://doi.org/10.1016/j.syapm.2018.06.001

Sperfeld M, Diekert G, Studenik S (2018) Anaerobic aromatic compound degradation in Sulfuritalea hydrogenivorans sk43H. FEMS Microbiol Ecol 95https://doi.org/10.1093/femsec/fiy199

Székely AJ, Sipos R, Berta B, et al (2009) DGGE and T-RFLP analysis of bacterial succession during mushroom compost production and sequence-aided T-RFLP profile of mature compost. Microb Ecol 57https://doi.org/10.1007/s00248-008-9424-5

Táncsics A, Szoboszlay S, Szabó I et al (2012) Quantification of subfamily I.2.C catechol 2,3-dioxygenase mRNA transcripts in groundwater samples of an oxygen-limited BTEX-contaminated site. Environ Sci Technol 46:232-240. https://doi.org/10.1021/ es201842h

Táncsics A, Farkas M, Szoboszlay S et al (2013) One-year monitoring of meta-cleavage dioxygenase gene expression and microbial community dynamics reveals the relevance of subfamily I.2.C extradiol dioxygenases in hypoxic. BTEX-Contaminated Groundwater Syst Appl Microbiol 36:339-350. https://doi.org/10.1016/j. syapm.2013.03.008

Táncsics A, Farkas M, Horváth B et al (2020) Genome analysis provides insights into microaerobic toluene-degradation pathway of Zoogloea oleivorans BucT. Arch Microbiol 202:421-426. https:// doi.org/10.1007/s00203-019-01743-8
Táncsics A, Szabó I, Baka E, et al (2010) Investigation of catechol 2,3-dioxygenase and 16S rRNA gene diversity in hypoxic, petroleum hydrocarbon contaminated groundwater. Syst Appl Microbiol 33https://doi.org/10.1016/j.syapm.2010.08.005

Tatusova T, DiCuccio M, Badretdin A et al (2016) NCBI prokaryotic genome annotation pipeline. Nucleic Acids Res 44:6614-6624. https://doi.org/10.1093/nar/gkw569

Tindall BJ, Rosselló-Móra R, Busse HJ, et al (2010) Notes on the characterization of prokaryote strains for taxonomic purposes. Int $\mathrm{J}$ Syst Evol Microbiol 60https://doi.org/10.1099/ijs.0.016949-0

US EPA-United States Environmental Protection Agency (2012) Toxic Release Inventory -Releases: chemical report-xylenes. 2012

Vallenet D, Engelen S, Mornico D, et al (2009) MicroScope: a platform for microbial genome annotation and comparative genomics. Database 2009https://doi.org/10.1093/database/bap021

Vallenet D, Labarre L, Rouy Z, et al MaGe: a microbial genome annotation system supported by synteny results. https://doi.org/10. 1093/nar/gkj406

Varjani SJ, Upasani VN (2016) Biodegradation of petroleum hydrocarbons by oleophilic strain of Pseudomonas aeruginosa NCIM 5514. Bioresour Technol 222https://doi.org/10.1016/j.biortech. 2016.10.006

Vidali M (2001) Bioremediation. An overview. In: Pure and Applied Chemistry

Vieira PA, Vieira RB, de França FP, Cardoso VL (2007) Biodegradation of effluent contaminated with diesel fuel and gasoline. $\mathrm{J}$ Hazard Mater 140https://doi.org/10.1016/j.jhazmat.2006.06.048

Wang X, Wang Q, Li S, Li W (2015) Degradation pathway and kinetic analysis for $\mathrm{p}$-xylene removal by a novel Pandoraea sp. strain WL1 and its application in a biotrickling filter. J Hazard Mater 288:. https://doi.org/10.1016/j.jhazmat.2015.02.019

Xu L, Wang H-T, Zhang J-X, et al (2020) Flavobacterium alkalisoli sp. nov., isolated from rhizosphere soil of Suaeda salsa. Int J Syst Evol Microbiol. https://doi.org/10.1099/ijsem.0.004255

Yan S, Zhou Q (2011) Toxic effects of Hydrilla verticillata exposed to toluene, ethylbenzene and xylene and safety assessment for protecting aquatic macrophytes. Chemosphere 85https://doi.org/ 10.1016/j.chemosphere.2011.07.040

Yeom SH, Daugulis AJ (2001) Benzene degradation in a two-phase partitioning bioreactor by Alcaligenes xylosoxidans Y234. Process Biochem 36https://doi.org/10.1016/S0032-9592(00)00277-6

Publisher's Note Springer Nature remains neutral with regard to jurisdictional claims in published maps and institutional affiliations. 